\section{Anti-aflatoxin B1 effects of Shirazi thyme (Zataria multiflora) in broilers: evaluation of performance and liver histopathology}

\author{
Omid Fani Makki, ${ }^{1}$ Arash Omidi,2 \\ Hossein Ansari Nik, ${ }^{3}$ \\ Seyed Ahmad Hasheminejad, 4 \\ Seyed Morteza Hosseini Senjedak 5 \\ 1Department of Animal Sciences, Faculty \\ of Agriculture, University of Birjand; \\ Research and Development Office, Zarin \\ Gostar Sarina Company, Khorasan Razavi, \\ Kashmar; 2Department of Animal Health \\ Management, School of Veterinary \\ Medicine, Shiraz University; ${ }^{3}$ Research \\ Center of Special Domestic Animal, \\ University of Zabol; 4University of \\ Applied Science and Technology, Jahad \\ Daneshgahi; Planning and Information \\ Office, Zarin Gostar Sarina Company, \\ Khorasan Razavi; 5Hazrat-e Abolfazl \\ Hospital, Nursing and Midwifery School, \\ Mashhad University of Medical Sciences, \\ Kashmar, Iran
}

\section{Abstract}

An experiment was conducted to study the effect of Zataria multifora (ZM) on the performance and liver histopathology of broiler chickens contaminated with aflatoxin $B_{1}$ (AFB1). One hundred and sixty Ross 308 male broilers (one-day-old) were divided into four treatment groups with four replicates with 10 birds in each replicate. The chickens were reared on the floor for 35 days. The groups were contaminated with AFB1 at two different concentrations, i.e., 0 and $1000 \mathrm{ppb}$, and fed $\mathrm{ZM}$ in their feed at the concentrations of 0 and 20 gr Kg1. The evaluated performance parameters were subjected to a completely randomized design with a $2 \times 2$ factorial arrangement of the treatments using SAS software (version 9/1). AFB1 had a statistical lowering effects on the feed intake, body weight, body weight gain and average weight of the carcass, thigh, chest, bursa of fabricius, back and neck. Also, the weights of liver, gizzard, pancreas, proventriculus, abdominal fat, full intestine, and heart were increased with AFB1 $(\mathrm{P}<0.05)$. In histopathological evaluations, the liver of chickens that received feed containing AFB1 showed multifocal and varied cytoplasmic vacuolization, severe fatty change, degenerating foci, fibrosis of the portal regions, and bile duct hyperplasia. The variables that were evaluated in this study showed that ZM had significant efficacy in diminishing the aflatoxins negative effects on the chickens.

\section{Introduction}

Aflatoxins (AFs) are a major group of mycotoxins that are produced by certain species of Aspergillus, i.e., A. flavus, A. parasiticus, Penicillium and Rhizopus spp. Among this group, A. parasiticus is the most common fungus, and A. flavus produces the highest amount of aflatoxin $B_{1}$ (AFB1). 1,2 Common AFs in the poultry industry are $\mathrm{B}_{1}, \mathrm{~B}_{2}, \mathrm{G}_{1}$, and $\mathrm{G}_{2}$, and the most prevalent aflatoxicosis is caused by AFB1.1-3 The toxic effects of AFs arise primarily from the binding of their particular epoxide derivation to deoxyribonucleic acid (DNA). 4,5 Also, the toxic effects of AFB1 can be either acute or chronic, based on the dosage and duration of usage. ${ }^{1,3}$ Exposure to AFs may lead to one or more biological activities, such as oxidative stress, acute toxicity, teratogenicity, mutagenicity, and carcinogenicity. ${ }^{6}$ Zataria multiflora Boiss (ZM) is a thyme-like plant that belongs to the Lamiaceae family. This plant has the vernacular name of Avishan-eShirazi (Shirazi thyme), and it is a valuable medicinal plant in Iran. ${ }^{7} \mathrm{ZM}$ is composed of a variety of compounds, including alpha-pinene, alpha-thyjene, thymol, cis-sabinene hydrate, para cymene, 1.8-cineole, myrcene, and sabinene. ${ }^{8}$ Probably, the presence of phenolic compounds, such as thymol and carvacrol, as the main compounds results in effective antiA. flavus and anti-A. parasiticus properties.9,10 A few studies have been conducted to determine the anti-fungal effects of ZM on histopathological changes in and the functioning of the liver in broilers infected with AFs. The main target organ for AFs is the liver. ${ }^{5,11}$ AFB1 causes pathological injuries to the liver.12 Chand and colleagues ${ }^{13}$ reported that giving broilers feed containing $80 \mu \mathrm{g} \mathrm{kg-1}$ of AFB1 alone, can decrease the FI and body weight. 13 This experiment was performed to assess the protective effects of ZM on the performance of the liver as well as any morphological and histopathological changes that occurred in the livers of chickens infected with AFB1.

\section{Materials and Methods}

\section{Experimental chickens and diets}

In this study, we used three different feeds for birds, depending on their age, i.e., i) starter feed (1-14 days); ii) grower feed (15-28 days); and iii) finisher feed (29-35 days) (Table 1). The different feeds were set based on the broilers' requirements according to the recommen-
Correspondence: Omid Fani Makki, Research and Development Office, Zarin Gostar Sarina Company, Khorasan Razavi Province, PO Box: 96716-68851, Kashmar, Iran.

E-mail: ofanimakki@birjand.ac.ir

Key words: Aflatoxin; Shirazi thyme (Zataria multifora); Broilers; Histopathology; Morphology.

Acknowledgements: all animals received humane care in compliance with the guidelines of Research Centers of Special Domestic Animals at Shiraz and Zabol Universities, Iran.

Contributions: the authors contributed equally.

Conflict of interest: the authors declare no potential conflict of interest.

Received for publication: 29 June 2016.

Accepted for publication: 5 August 2016.

This work is licensed under a Creative Commons Attribution NonCommercial 4.0 License (CC BYNC 4.0).

(C) Copyright O. F. Makki et al., 2016

Licensee PAGEPress srl, Italy

Veterinary Science Development 2016; 6:6090

doi:10.4081/vsd.2016.6090

dations of the Ross 308 Company, and they were adjusted by the User-Friendly Feed Formulation Program (UFFDA) software. The study included 160 broiler chickens acquired from Ross 308 and that were reared on the floor until they were 35 days old. They were divided randomly into four groups with four replicates and 10 birds in each experimental unit. This study was conducted as a $2 \times 2$ factorial plan and based on a completely randomized design. The experimental groups were as follows: i) the control group with the basal diet alone; ii) the basal diet contaminated with 1000 ppb AFB1; iii) the basal diet plus $20 \mathrm{~g} \mathrm{~kg}^{-1} \mathrm{ZM}$; and iv) the basal diet containing $20 \mathrm{~g} \mathrm{~kg}^{-1}$ of ZM and 1000 ppb AFB1. ZM and AFB1 were administered daily by gavage to ensure the administration of the correct dose. The experiment was approved by the animal welfare committee in the Research Center for Special Domestic Animals, Zabol University, Zabol, Iran.

\section{Performance variables}

Feed intake (FI), body weight (BW), and body weight gain (BWG) were measured every week for each replicate of groups. Feed conversion ratio (FCR) was calculated.14 At the end of the study, after four hours without any feed, two male birds from each experimental unit were randomly selected and slaughtered by cervical dislocation. Immediately after slaughtering and defeathering, they were eviscerated, and the relative weight of the carcass, 
thighs, and breasts to the percent of carcass weight and the ratio of the weight of internal and sensitive organs to $100 \mathrm{~g}$ of carcass weight were determined. The relative weight of the carcass, thigh, breast, full intestine, abdominal fat, and sensitive internal organ weights were recorded.

\section{Morphological and histopathologi- cal variables}

After slaughter, chicken livers from each replicate were weighted. The liver tissues were examined morphologically and then fixed in natural formalin buffer 10\% (Merck, Germany) for histopathologic studies. The tissues were immersed in paraffin, and blocks were made. The paraffin blocks were cut and colored with hematoxylin and eosin (H\&E stain), and slides were prepared and studied with light microscopy. 15

\section{Statistical analyses}

The data were analyzed in a completely randomized design with a $2 \times 2$ factorial arrangement of the treatments using statistical analysis software (SAS).16 The data were compared with Tukey-Kramer post hoc tests. Least squares means \pm standard errors were reported.

\section{Results}

\section{Performance}

The results of the chickens' performance are presented in Supplementary Tables S1-6. Feeding the chickens different levels of AFB1 had a significant effect on the amount of FI, $\mathrm{BW}$, and BWG $(\mathrm{P}<0.01)$. In contrast, statistical analysis results related to interactions of FI at the ends of the first through the fourth weeks of the study demonstrated no significant changes compared to the controls (Supplementary Table S1). The results of the statistical analysis related to interaction effects of BW and BWG at the end of the first through the third weeks of the experiment showed no significant effects of the consumption of the experimental feeds compared to the weights of the chickens that received the control feed (Supplementary Tables S2 and S3, respectively). The results of this study indicated that feeding with different levels of AFB1 plus ZM had no effect on FCR in chickens during the experimental period (Supplementary Table S4) ( $\mathrm{P}>0.05)$. The results of interaction effects related to carcass variables at the end of the period ( 35 days) indicated that there were no significant changes in the composition of the carcasses; for example, in comparison with the controls, there were no significant changes in the weights of the legs, wings, and spleens (Supplementary Tables S5 and S6) of the treated chickens. However, the different levels of AFB1 in the feeds did results in weight changes in abdominal fat, full intestine, liver, gizzard, pancreas, proventriculus, heart, and bursa of Fabricius $(\mathrm{P}<0.05)$.
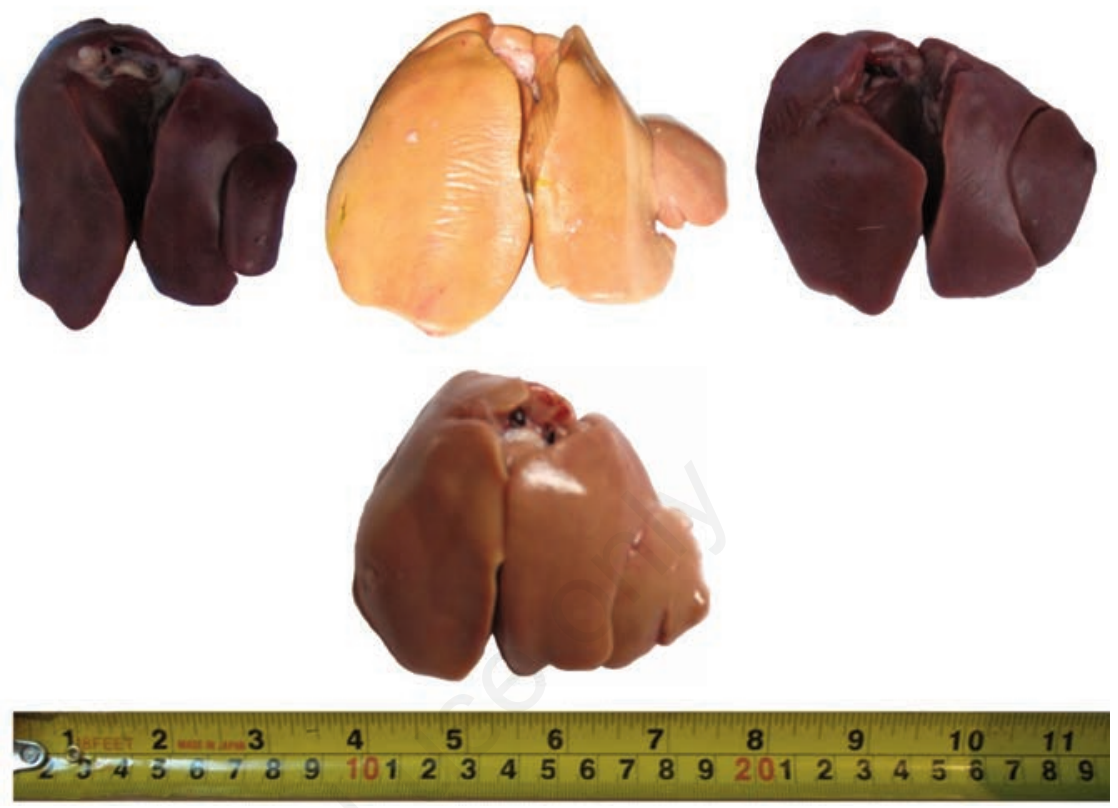

Figure 1. Liver morphology of birds intoxicated with aflatoxin $B_{1}$ (AFB1): control (upper left); AFB1 toxicosis: paleness and yellow discoloration (middle and upper); ZM: normal liver morphology (upper right); AFB1 + Shirazi thyme (Zataria multifora, ZM): yellow discoloration (bottom).

Table 1. Composition of the starter, grower and finisher diets fed to broilers (as fed).

\begin{tabular}{lccc} 
Feed stuffs & $\begin{array}{c}\text { Starter period } \\
(1-14 \text { day })\end{array}$ & $\begin{array}{c}\text { Grower period } \\
(15-28 \text { day })\end{array}$ & $\begin{array}{c}\text { Finisher period } \\
(29-35)\end{array}$ \\
Corn & 54.43 & 50.42 & 45.99 \\
Wheat & - & 10.00 & 20.00 \\
\hline Soybean meal (44\% CP) & 35.00 & 30.29 & 25.56 \\
Fish meal (60\% CP) & 3.070 & 2.040 & 1.060 \\
\hline Soybean fat & 3.290 & 3.570 & 3.760 \\
Di-calcium phosphate & 1.730 & 1.470 & 1.490 \\
\hline Oyster shell & 1.160 & 1.040 & 1.020 \\
Mineral premix & 0.500 & 0.500 & 0.500 \\
\hline Vitamin premix & 0.500 & 0.500 \\
Salt & 0.500 & 0.210 & 0.211 \\
\hline DL-methionine & 0.210 & 0.280 & 0.241 \\
L-lysine & 0.350 & 0.190 & 0.211 \\
\hline Analyzed values & 0.240 & & \\
$\quad$ ME (Kcal kg-1) & & 3050 & 3100 \\
CP (\%) & 2980 & 20.00 & 18.00 \\
Lys (\%) & 22.00 & 1.240 & 1.090 \\
Met + Cys (\%) & 1.430 & 0.950 & 0.860 \\
Thr (\%) & 1.070 & 0.280 & 0.260 \\
Ca (\%) & 0.310 & 0.900 & 0.850 \\
P (\%) & 1.050 & 0.450 & 0.420 \\
\hline
\end{tabular}

*Provided at the following rates per kilogram of diet: $\mathrm{Mn}$ (from $\mathrm{MnSO}_{4}-\mathrm{H}_{2} \mathrm{O}$ ), $0.63 \mathrm{mg}$; $\mathrm{Zn}$ (from $\mathrm{ZnO}$ ), $0.52 \mathrm{mg}$; $\mathrm{Fe}$ (from $\mathrm{FeSO}_{4}-7 \mathrm{H}_{2} \mathrm{O}$ ), $22 \mathrm{mg}$; $\mathrm{Cu}$ (from $\mathrm{CuSO}_{4}-5 \mathrm{H}_{2} \mathrm{O}$ ), $3 \mathrm{mg}$; I (from Ca $\left(\mathrm{IO}_{3}\right) 2-\mathrm{H}_{2} \mathrm{O}$ ), $0.63 \mathrm{mg}$; Se, $0.08 \mathrm{mg}$ (from sodium selenite). ${ }^{\circ}$ Provided at the following rates per $\mathrm{kg}$ of diet: $3400 \mathrm{IU}$ vitamin $\mathrm{A}, 800 \mathrm{IU}$ vitamin $\mathrm{D}_{3}, 11 \mathrm{IU}$ vitamin $\mathrm{E}, 0.74 \mathrm{mg}$ vitamin $\mathrm{B}_{1}, 4.3 \mathrm{mg}$ vitamin $\mathrm{B}_{2}, 0.4 \mathrm{mg}$ vitamin $\mathrm{B}_{3}, 1.6 \mathrm{mg}$ vitamin $\mathrm{B}_{6}, 0.41 \mathrm{mg}$ vita$\min \mathrm{B}_{12}, 1.8 \mathrm{mg}$ vitamin $\mathrm{K}_{3}, 0.6 \mathrm{mg}$ folic acid, $1.8 \mathrm{mg} \mathrm{H} 2,200 \mathrm{mg}$ Choline chloride. 
ings in the liver sections of broilers that received feed with 1000 ppb AFB1 showed multi-nuclear cells in the portal area (Figure 3A), hemorrhage, and hyperplasia (Figure 3B), necrosis, and fat decaying in hepatocytes (Figure 3C). These pathologic findings were more obvious in chickens that received 1000 ppb of AFB1 compared to the chickens that received feed containing $1000 \mathrm{ppb}$ of AFB1 plus $20 \mathrm{~g} \mathrm{Kg}^{-1}$ of ZM (Figure 4).

\section{Discussion and Conclusions}

In accordance with some research, no changes were observed in the appearance of the treated chickens in the first and second weeks of study.1,5 Beginning with the third week, we observed the gradual development of low growth rate, feathers confusion, pallor crown, and aggressive and nervous symptoms in chickens that received feed containing only 1000 ppb AFB1 compared to chickens that received the control feed.11,13 In comparison with chickens that received the control feed, no similar symptoms were observed in birds fed with ZM. ${ }^{10}$ However, FI in chickens that received feeds with $1000 \mathrm{ppb}$ AFB1 was lower than other groups in the fifth week $(\mathrm{P}<0.01)$. The use of ZM in the diets ( $20 \mathrm{~g} \mathrm{Kg}^{-1}$ of feed) increased the FI of contaminated diets with 1000 ppb AFB1. Some authors have reported that the phenolic compounds found in ZM, such as thymol and carvacrol, can increase FI and $\mathrm{BW}$ in rats that received AFB1.10,17 Also, a few studies have been performed to determine the interaction effects of AFB1 plus ZM in humans and other animal species. After the end of the third week, the results demonstrated that the average BW and BWG in the treated chickens that took diets contaminated with

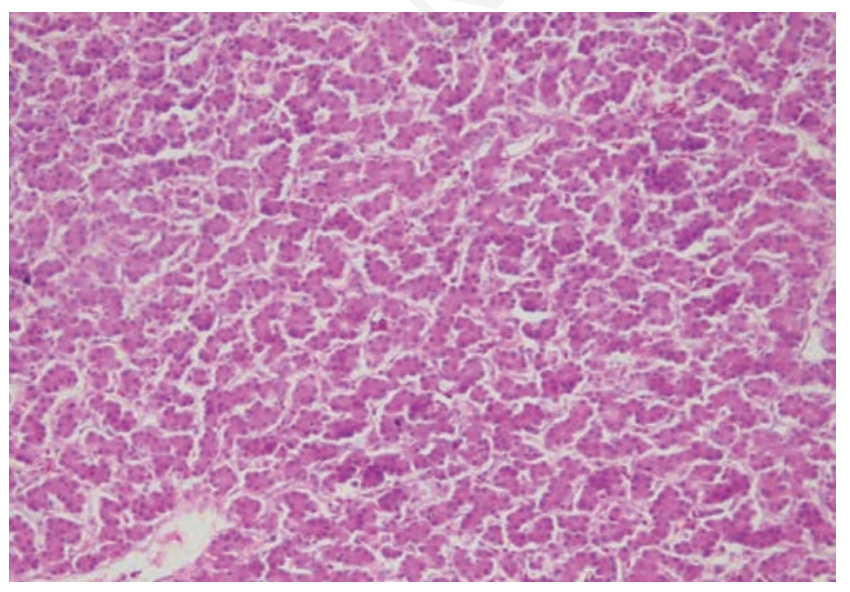

Figure 2. Normal histological appearance of the liver from a control broiler chicken (fed basal diet alone), hematoxylin and eosin $100 \times$.
1000 ppb AFB1 were significantly lower than the control $(\mathrm{P}<0.01)$. The main effects of the FI and BW of the chicks fed only with ZM were consistent with the findings of Cross and colleagues; 18 they fed chickens different levels of phenolic ZM compounds as beverages. However, the results were inconsistent with those of other authors. ${ }^{19,20}$ Nevertheless, with increasing levels of AFB1 plus ZM at the first through the fifth week of this study (35 days old), FCR did not change ( $P>0.05)$. The effective impacts of plant products and derivatives on the growth and functional properties relate to several variables, including the stimulatory effects of these products on the gastrointestinal digestion process, stimulating and increasing the secretion of digestive enzymes, increasing the efficiency of nutrient feed,
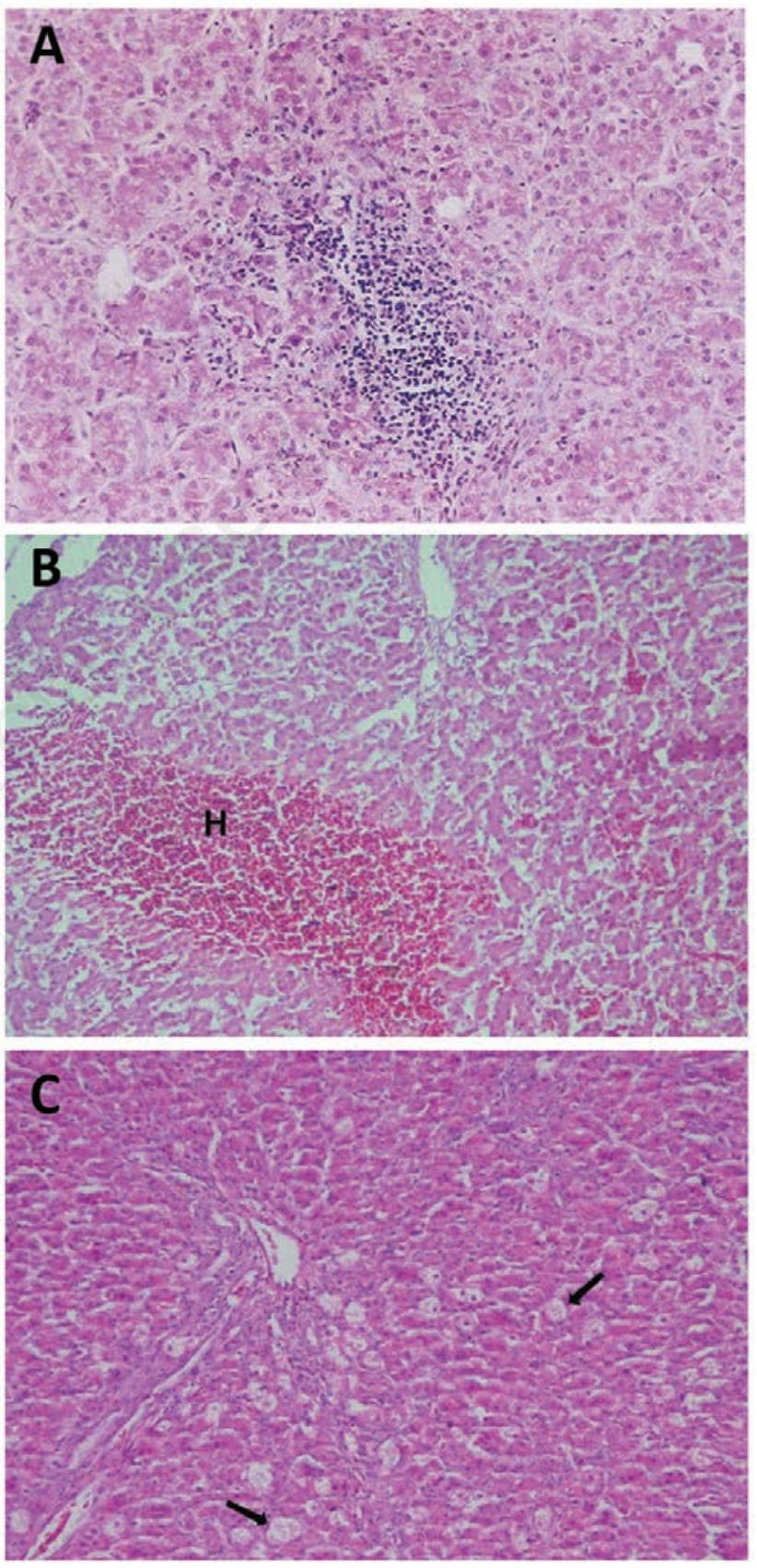

Figure 3. A) Parenchymal and mononuclear cell aggregation in liver of chicken fed $1000 \mathrm{ppb}$ AFB1 contaminated diet, [hematoxylin and eosin (H\&E) 100x]. B) Liver histology from a broiler chicken contaminated with $1000 \mathrm{ppb}$ AFB1. Note the hemorrhage $(\mathrm{H})$ in the liver tissue, $(\mathrm{H} \& \mathrm{E} \times 100)$. C) Liver histology from a broiler chicken contaminated with $1000 \mathrm{ppb}$ AFB1. A severe degeneration of the hepatocytes and loss of some nuclei (arrows) were observed, $(\mathrm{H} \& \mathrm{E} \times 100)$. 


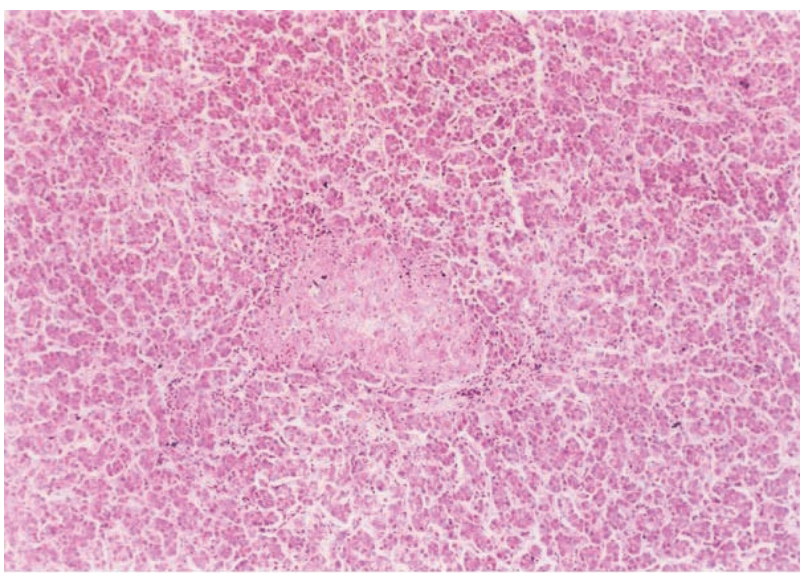

Figure 4. Restoration in focal area of hepatic necrosis in chicken fed $1000 \mathrm{ppb}$ Aflatoxins $+20 \mathrm{gr} \mathrm{kg}^{-1}$ Shirazi thyme (Zataria multifora); hematoxylin and eosin $\times 100$.

increasing the efficiency of the liver, and increasing the appetite due to flavors. ${ }^{21}$

The statistical analysis of carcass efficiency data presented as a proportion of the live weight showed a significant decrease $(\mathrm{P}<0.01)$ in the carcass ratio, thighs, breast, back, and necks of the chickens that received feeds that were contaminated with $1000 \mathrm{ppb}$ of AFB1 compared to chickens that received feeds containing $20 \mathrm{~g} \mathrm{Kg}^{-1}$ of $\mathrm{ZM}$ alone or combined with 1000 ppb AFB1. Other researchers have observed a significant decrease in the weights of the breasts and thighs of the treated chickens that received feed containing AFB1 alone compared to chickens that received the control feed. ${ }^{2,21}$ The results showed that increasing the AFB1 concentrations in the feeds increased the variability of the weight levels (abdominal fat, full intestine, liver, gizzard, pancreas, proventriculus, and heart) and, on the contrary, significantly decreased the weight of the bursa of Fabricius compared to the controls. Miazzo and colleagues 22 reported that feeding with only $2.5 \mathrm{ppm}$ of aflatoxin caused a significant increase in the weights of most of the commercial male Ross 308 broiler chickens' organs (liver, spleen, kidney, and gizzard). Also, Kermanshahi and colleagues ${ }^{23}$ reported that feeding with 500 and $1000 \mu \mathrm{gg}$ ${ }^{1}$ AFB1 caused a significant increase in the relative weights of the livers and brains in male Ross 308 broiler chickens. No results have been reported concerning the effects of ZM and AFB1 on morphological and histopathological changes in the broiler chicks' liver tissues. The livers of birds that received feed contaminated with AFB1, were pale and yellowish. Pale livers were more obvious in the birds fed with AFB1 alone. Our observations of liver damage caused by AFB1 were consistent with those of some other authors. ${ }^{24-26}$ The supplementation of feeds contaminated with 1000 ppb AFB1 plus $20 \mathrm{~g} \mathrm{Kg}^{-1}$ of ZM indicated that ZM significantly decreased the effects of AFB1 on the experimental birds. These results are in accordance with some other authors' reports on Japanese quail ${ }^{24}$ and rats.9,10 These necrotic centers were surrounded by a delicate connective tissue and consisted of large multi-nuclear cells and hyperplasia without any fat vacuoles. $9,24,25$ Some liver cells contained a lot of large nuclei and chromatin (megasitosis).9,10,24 Fibrosis of the portal area was observed to be increasing the connective tissue with the proliferation of small bile ducts. ${ }^{9,10,24-26}$ The histological findings confirmed the biochemical results and indicated that AFs induced severe histological changes in the hepatic tissues. Similar histological changes in the liver have been documented previously in rats. $4,6,27$ The livers of the birds that received feeds containing $20 \mathrm{~g} \mathrm{~kg}^{-1}$ ZM were roughly normal and showed discrete diffusion cell swelling with mild effects on the hepatocytes along with mild cytoplasmic changes. However, mild positive effects on hepatocytes, infiltrating of mononuclear cells, and hyperplasia were observed in the livers of the birds that received $20 \mathrm{~g} \mathrm{Kg}^{-1} \mathrm{ZM}$ and 1000 ppb AFB1. The improved histological and histochemical appearance of the liver in broilers fed with AFB1-contaminated feed and treated with $\mathrm{ZM}$ revealed the protective role of the $\mathrm{ZM}$ against AFB1-induced liver injury. ${ }^{28}$ These effects may be related mainly to the anti-oxidant and free radical scavenging properties of ZM.

In conclusion, the phenolic compounds that exist in the seeds of ZM can ameliorate the histopathological liver damages caused by AFB1. According to this research, $20 \mathrm{~g} \mathrm{Kg}^{-1}$ of $\mathrm{ZM}$ is effective. Further investigations in this field in the future are recommended.

\section{References}

1. Fani Makki 0, Afzali N, Omidi A. Effect of milk thistle seeds (Silybum marianum L.) on the immune system, intestinal related variables, appearance and mortality of broilers contaminated with Aflatoxin B1. J Herb Drug 2013;4:33-8.

2. Yunus AW, Razzazi-Fazeli E, Bohm J. Aflatoxin B1 in affecting broiler's performance, immunity, and gastrointestinal tract: a review of history and contemporary issues. Toxins 2011;3:566-90.

3. Fani Makki 0, Afzali N, Omidi A, Shibak A. Comparison of Aflatoxin B1 production by Aspergillus flavus and Aspergillus parasiticus under various conditions of temperature, light and pH. Armaghane-danesh (YUMSJ) 2013;18:210-8.

4. Rawal S, Kim JE, Coulombe JR. Aflatoxin B1 in poultry: toxicology, metabolism and prevention. Res Vet Sci 2010;89:325-31.

5. Tedesco D, Steidler S, Galletti S, et al. Efficacy of silymarin-phospholipid complex in reducing the toxicity of aflatoxin B1 in broiler chicks. Poult Sci 2004;83:1839-43.

6. Abdel-Wahhab MA, Hassan NS, El-Kady AA, et al. Red ginseng extract protects against aflatoxin B1 and fumonisins-induced hepatic pre-cancerous lesions in rats. Food Chem Toxicol 2010;48:733-42.

7. Fazeli MR, Amin G, Attari MMA, et al. Antimicrobial activities of Iranian sumac and avishan-e Shirazi (Zataria multiflora L.) against some food-borne bacteria. Food Control 2007;18:646-9.

8. Imelouane B, Amhamdi H, Wathelet JP, et al. Chemical composition and antimicrobial activity of essential oil of thyme (Thymus vulgaris) from Eastern Morocco. Int J Agri Biol 2009;11:205-8.

9. El-Nekeety AA, Mohamed SR, Hathout AS, et al. Antioxidant properties of (Thymus vulgaris) oil against aflatoxin-induce oxidative stress in male rats. Toxicon 2011;57:984-91.

10. Hamzawy MA, EL-Denshary ESM, Hassan NS, et al. Antioxidant and hepatorenoprotective effects on thyme vulgaris extract in rats during aflatoxicosis. Global $\mathrm{J}$ Pharmacol 2012;6:106-17.

11. Fani makki 0, Afzali N, Omidi A, et al. The effect of different levels of Aflatoxin B1 on intestinal length, blood parameters and immune system in broiler chickens. J Vet Microbiol 2013;9:73-9.

12. Arranz I, Sizoo E, Van Egmond H, et al. Determination of aflatoxin B1 in medical herbs: interlaboratory study. J AOAC Int 2006;89:595-605. 
13. Chand N, Durrani FR, Qureshi MS, et al. Protective effects of milk thistle (Silybum marianum) against aflatoxin B1 in broiler chicks. Asian Australas J Anim Sci 2011;24:1011-8.

14. Pym RAE, Nicholls PJ. Selection for food conversion in broilers: direct and correlated responses to selection for body weight gain, food consumption and food conversion ratio. Brit Poult Sci 1979;20:73-86.

15. Drury RAV, Wallington EA. Carltons histological techniques, $5^{\text {th }}$. New York: Oxford University Press, Pronto; 1980. pp 206.

16. SAS Institute. SAS User's Guide: Statistics, Version 6. SAS Institute. Inc. Cary. NC. 2001.

17. Ramezani M, Hosseinzadeh H, Samizadeh S. Antinociceptive effects of Zataria multiflora Boiss fractions in mice. J ethnopharmacol 2004;91:167-70.

18. Cross DE, McDevitt RM, Hillman K, Acamovic T. The effect of herbs and their associated essential oils on performance, dietary digestibility and gut microflora in chickens from 7 to 28 days of age. Brit Poult Sci 2007;48:496-506.

19. Ocak N, Erener G, Burak Ak F, et al. Performance of broilers fed diets supple- mented with dry peppermint (Mentha piperita L.) or thyme (Thymus vulgaris L.) leaves as growth promoter source. Czech J Anim Sci 2008;53:169.

20. Toghyani M, Tohidi M, Gheisari AA, Tabeidian SA. Performance, immunity, serum biochemical and hematological parameters in broiler chicks fed dietary thyme as alternative for an antibiotic growth promoter. Afr J Biotechnol 2010;9:6819-25.

21. Kalantar M, Saki AA, Zamani P, Aliarabi H. Effect of drinking thyme essence on performance, energy and protein efficiency and economical indices of broiler chickens. Anim Sci J 2011;92:59-67.

22. Miazzo R, Peralta MF, Magnoli C, et al. Efficacy of sodium bentonite as a detoxifier of broiler feed contaminated with aflatoxin and fumonisin. Poult Sci 2005;84:18.

23. Kermanshahi H, Hazegh AR, Afzali N. Effect of Sodium Bentonite in broiler chickens fed diets contaminated with Anatoxin B1. J Anim Vet Adv 2009;8:16316.

24. Shanks ET, Statkiewicz WR, Llwelleyn GC, Dashek WV. Tissue distribution and hepat- ic ultrastructural effects of aflatoxin B1 in Japanese quail. Pol Arch Weter 1986;26: 117-31.

25. Rosa CA, Miazzo R, Magnoli C, et al. Evaluation of the efficacy of bentonite from the south of Argentina to ameliorate the toxic effects of aflatoxin in broilers. Poult Sci 2001;80:139-44.

26. Karaman M, Basmacioglu H, Ortatatli M, Oguz H. Evaluation of the detoxifying effect of yeast glucomannan on aflatoxicosis in broilers as assessed by gross examination and histopathology. Brit Poult Sci 2005;46:394-400.

27. Miura K, Kikuzaki H, Nakatani N. Antioxidant activity of chemical components from sage (Salvia officinalis L.) and thyme (Thymus vulgaris L.) measured by the oil stability index method. J Agri Food Chem 2002;50:1845-51.

28. Loziene K, Venskutonis PR, Sipailiene A, Labokas J. Radical scavenging and antibacterial properties of the extracts from different (Thymus pulegioides L.) chemotypes. Food Chem 2007;103:546-59. 